\title{
EDUCAÇÃO E CORPOREIDADE: UM NOVO OLHAR SOBRE O CORPO
}

\section{M. FREIRE' ${ }^{1}$ e M. H. de A. DANTAS ${ }^{2}$}

${ }^{1}$ Profa de Educação Física- Instituto Federal de Educação, Ciência e Tecnologia do Rio Grande do Norte Ivanilda.freire@ifrn.edu.br

${ }^{2}$ Profa de Educação Física - Secretaria Municipal de Educação/RN - Escola Municipal Terezinha Paulino marayahdantas@yahoo.com.br

\section{Artigo submetido em outubro/2011 e aceito em setembro/2012}

\section{RESUMO}

O presente texto é resultado das discussões desenvolvidas no projeto de pesquisa "Um novo olhar sobre o corpo" realizado com alunos da Escola Municipal Terezinha Paulino, da cidade do Natal. O referido projeto teve como objetivo principal refletir sobre a concepção de corpo em nossa sociedade, em especial aquela difundida pela mídia. Metodologicamente, nossa pesquisa foi realizada durante as aulas de educação física através de exposições dialógicas; leituras; seminários; palestras; e vivencia de diferentes técnicas corporais. Tais procedimentos se tornaram essenciais para conhecermos e refletirmos sobre alguns aspectos relacionados ao corpo, como por exemplo: beleza, saúde, sensualidade, entre outros. Acreditamos que nossa investigação possibilitou elucidar, juntamente com os alunos, saberes e conhecimentos ligados ao corpo e a corporeidade, ajudando a superar uma visão alienante e limitada da temática em questão.

PALAVRAS-CHAVE: Corpo, Corporeidade, Mídia, prática pedagógica.

\section{EDUCATION AND CORPORATE: A NEW LOOK ON THE BODY}

\section{ABSTRACT}

This text is the result of the discussions developed in the research project "A new look at the body" conducted with students of the Municipal School Terezinha Paulino, the city of Natal. This project aimed to reflect on the conception of body in our society, especially those spread by the media. Methodologically, our research was conducted during physical education classes through exhibitions dialogical, readings, seminars, lectures, and experiences of different physical techniques. Such procedures have become essential to know and reflect on some aspects related to the body, such as: Beauty, Health, sensuality, among others. We believe that our investigation led us to clarify, along with students, knowledge and expertise related to the body and embodiment, helping to overcome alienation and limited vision of the theme in question.

KEY-WORDS: Body, Corporeality, media, teaching practice 


\section{EDUCAÇÃO E CORPOREIDADE: UM NOVO OLHAR SOBRE O CORPO}

\section{INTRODUÇÃO}

Observamos na contemporaneidade um interesse exacerbado pelo corpo. No entanto, tal preocupação geralmente é restrita a aspectos relacionados a saúde, sensualidade e a busca de beleza, com finalidade de corrigir o corpo. Nesse contexto, surge o interesse pelos tratamentos cosméticos de beleza, das cirurgias plásticas, entre outros, desencadeando um consumismo desenfreado. Essas atitudes fazem com que o corpo hoje seja "vivido como acessório da pessoa, artefato da presença, implicado em uma encenação de si que alimenta uma vontade de se reapropriar de sua existência, de criar uma identidade provisória mais favorável. O corpo é então submetido ao design às vezes radical que nada deixa inculto" (LE BETRON, 2003, p. 22).

Tal expectativa de corpo vem tornando-se hegemônica na sociedade hodierna e a tecnociência com seus métodos, formas de intervenções cada dia mais avançadas vem socorrer esse corpo, a fim de possibilitar as metamorfoses corporais que atende as necessidades muitas vezes irrefletidas das pessoas. No pensamento do sujeito contemporâneo "o corpo é hoje um motivo de apresentação de si" (LE BRETON, 2003, p. 30). Vivemos no mundo da valorização da aparência física, o que somos vai depender da maneira que nos apresentamos, geralmente referenciados pela mídia, pois, é a partir desse modelo que seremos aceitos ou não pela sociedade.

Entretanto, vislumbramos um novo olhar sobre o corpo, considerando sua complexidade, tomando conhecimento da diversidade inerente aos indivíduos e também da sua cultura. Acreditamos que dessa forma será possível um (re) pensar das aspirações dos sujeitos e da sociedade. Como sugere Silva:

Situando-se na interconexão entre o mundo da cultura e o mundo da natureza, o corpo representa um importante foco de reflexão e de indicações em torno do renorteamento do eixo civilizatório, dada a vivência de uma crise de dimensões desconhecidas das até então, com implicações éticas e epistemológicas para o futuro da vida no planeta (SILVA, 2001, p.01).

Nesse contexto, a instituição escolar tem um importante papel a desenvolver: é fundamental que se abra um espaço para a construção de representações do corpo e dos valores que a ele se atribui. É importante perceber esse espaço como lugar privilegiado para refletir sobre a formação dos sujeitos, desmistificando estigmas, estereótipos, valores e atitudes, buscando assim, humanizar a prática pedagógica.

A vivência do ato educativo é uma experiência que se dá através do corpo na sua relação com os objetos da educação. O ser humano não pode se conhecer e nem conhecer, se não compreende a essência de sua existência. Existe uma grande necessidade de se desvendar a importância do corpo na educação. Nesse sentido, o professor deve orientar ações que levem os alunos a formar seus próprios significados de movimento e linguagem. Assim sendo, será necessário o conhecimento das questões relacionadas à corporeidade e sobre o contexto sócio- 
cultural em que as coisas acontecem.

Nesse sentido, acreditamos que uma reflexão mais substanciosa sobre o corpo deva superar a visão estereotipada socialmente construída que valoriza apenas os indicadores anteriormente descritos (saúde, sensualidade e beleza). Dessa forma, o objetivo principal desse estudo foi refletir sobre a concepção de corpo em nossa sociedade, em especial aquela difundida pela mídia, na tentativa de elucidar saberes e conhecimentos sobre o corpo e a corporeidade. $O$ estudo foi realizado com os alunos da Escola Municipal Terezinha Paulino, da cidade do Natal. Para atender os objetivos elencados, metodologicamente, realizamos exposições dialógicas; leituras; seminários; palestras; e vivencia de diferentes técnicas corporais. Tais procedimentos se tornaram essências para conhecermos e refletirmos sobre aspectos importantes relacionados à temática em questão.

\section{Concepção de corpo no âmbito da ciência}

A história do corpo, em geral tem sido pouco considerada. Por um lado os componentes clássicos da ciência, e por outro, a tradição judaico-cristão, ambas com uma visão dualista do homem que consideram como nobres a mente ou/e a alma e o corpo visualizado como algo pecaminoso, instrumento a ser manipulado pela ciência. Nas palavras de Sant'anna:

Enquanto a alma é pensada em termos positivo e dotada de imortalidade, o corpo permanece mortal, aquilo que impede o homem de conquistar na contemplação serena da vida. Considerado seu duplo vergonhoso, o corpo padece e está fadado a padecer, pois, diferentemente da alma, está submetido aos ciclos naturais, às flutuações do desejo aos perigos da corrupção (SANT'ANNA, 2001, p. 13).

Essa é a concepção de corpo que se firmou em nossa cultura, ou seja, mente/alma e corpo se afirmam como opostos. Com esse pensamento, a essência do corpo ficou no esquecimento e enaltecido pela sua materialidade. $O$ que se tornou fácil a sua representação como máquina e seu funcionamento ligado às leis da mecânica newtoniana, idéia clássica de Descartes. Dessa forma, o corpo vem sendo tratado como uma soma de partes, as quais podem ser compreendidas isoladamente. Tal concepção de corpo perdura até hoje.

\section{A simbologia do corpo estetizado}

O corpo vem sendo estudado a partir de diferentes práticas como: da medicina esportiva; da genética e hoje da medicina moderna, a biotecnologia, com vista à possibilidade exploratória para o consumo. A mídia contribui bastante nesse processo, determinando qual o estereótipo de corpo que deve predominar na sociedade, ditando valores, costumes e padrões de beleza. Os indivíduos envolvidos pelos apelos da mídia começam a perder a noção da sua essência significativa no mundo na busca por esse ideal de beleza. Aqueles que não podem se sujeitar aos apelos do consumo, muitas vezes, entra num estado de angustia, de baixa autoestima. 
O narcisismo tornou-se uma neurose coletiva, como "opção por um eixo civilizatório identificado por um etnocentrismo exacerbado, quanto do ponto de vista individual, com uma preocupação excessiva consigo mesmo, dada a busca pela identidade, tendo o desenvolvimento das tecnologias do corpo como um estado de culminância desse processo" (SILVA, 2001, ps. 83,84).

Nesses termos, o indivíduo não compreende aquilo que lhe é ou não inerente. A artificialidade do corpo é o caminho para o seu bem estar, os "cuidados" com o corpo torna-se uma exigência, com isso, o mercado de produtos e serviços para atender as perspectivas do corpo "perfeito", vão se expandindo. É através do corpo estetizado, remodelado pelas cirurgias plásticas, pelos implantes de silicone que os sujeitos se realizam. A racionalidade moderna impõe aos indivíduos à incorporação lógica da máquina, ignora a essência humana e aponta para uma desvalorização dos aspectos emocionais. "Vivemos uma cultura que desvaloriza as emoções, e não vemos o entrelaçamento cotidiano entre razão e emoção, que constitui nosso viver humano" (MATURANA, 1998, p.15).

\section{Um novo olhar sobre o corpo}

Dessas considerações, afirma-se cada vez mais a necessidade de uma fenomenologia do corpo que se funda pela essência do ser no mundo como forma de mediar seus conflitos e na contribuição que tem o jogo estésico das experiências vividas, apontando-se para um (re) pensar esse corpo e suas atitudes perante o consumismo, pois se chega o momento certo de se apropriar do eu, tornando-se ator de sua própria história encarnada nessa metamorfose transfigurada pela autonomia desse repensar. Assim sendo, proclama-se esse novo olhar que partiu de um corpo estetizado e tatuado de forma objetiva para um corpo elaborado pela autonomia do viver que se configura pelos códigos da sensibilidade perceptiva.

A busca por uma compreensão do corpo além da visão dualista que historicamente delegou ao corpo a condição de instrumento em relação à mente e/ou alma, aponta o estudo da corporeidade como concepção que restitui a unidade corpórea, ou seja, a relação do corpo com o mundo e a indivisibilidade corpo- mente-alma. De acordo com Porpino:

A partir do conceito de corporeidade é possível entender o corpo como possuidor de uma singularidade que somente se compreende na pluralidade da existência de outros corpos, e que é capaz de gerar conhecimento, autogerando-se, a cada momento, a partir da inevitabilidade da coexistência entre a sensibilidade e a razão. Assim, a corporeidade desvela o corpo em sua essência existencial complexa. Restitui a este a sua capacidade de gerar conhecimento, de reconhecer-se como sujeito da percepção, sendo ao mesmo tempo objeto percebido por outros corpos, numa época (século XX) em que a predominância do racionalismo ainda se faz presente (PORPINO, 2006, p. 63).

Como vimos, o corpo é um campo aberto gerador de conhecimentos. A noção corporeidade configurando uma linguagem sensível (instituída pelo corpo e a experiência de movimento), marcada por sentimentos; gestos, sensações; pensamentos aponta como nova 
possibilidade de compreender o corpo e o conhecimento. O estudo da corporeidade vem tornando-se um campo de reflexão de muitos pesquisadores comprometidos com a nova visão de corpo, como por exemplo: NÓBREGA (2003, 2005,2010), PORPINO (2006), entre outros.

Nesse contexto, apontamos para um novo olhar sobre o corpo. O corpo como espaço de visibilidade humana é também "lugar de inscrição e de criação da linguagem e da história" (NÓBREGA, 2003, p.131), não pode ser considerado apenas pelos seus aspectos: biológicos, funcional e estrutural. O corpo como apresentação do ser no mundo, requer um novo olhar, porque "O corpo em suas formas, ritmos e gestos é linguagem para si e para outro. Ambos corpo e linguagem articulam-se na expressão e na comunicação, é nessa unidade que a autenticidade da expressão encontra sua verdade" (GONÇALVES, 1994, p. 97).

A condição humana deve ser considerada também pela "sensibilidade afetiva, as emoções, os sentimentos, os impulsos sensíveis, o senso estético, etc." (SANTIN, 1993, p. 67). É necessário que se supere a visão unilateral que compreende o ser humano apenas pela racionalidade e vislumbre o homem em sua complexidade. Conhecer o ser humano é, antes de tudo, necessário situá-lo no mundo vivido. O conhecimento pertinente deve enfrentar a complexidade do fenômeno em questão, por se tratar do corpo vivo, humano.

Não resta dúvida quanto à importância da racionalidade científica para o progresso da nossa sociedade, da humanidade, mas há de se pensar a forma em que acontece esse desenvolvimento, visto que, põe em risco a vida do planeta e da humanidade. MORIN alerta:

As prodigiosas elucidações trazidas pelo conhecimento científico são acompanhadas pelas regressões cognitivas da especialização, que impede a percepção do contextual e do global. Os poderes derivados da ciência são não só benéficos, mas também destruidores, manipuladores e cegos (MORIN, 1997, p. 14).

Nesse sentido, apontamos para uma nova perspectiva em direção à complexidade dos fenômenos que abarque também os parâmetros não racionais como o sonho, o lúdico, o imaginário e o prazer dos sentidos. Apontamos o sensível como fonte de riqueza espiritual, fortalece o corpo. E que o corpo, enquanto metáfora dos sentidos é um resumo do corpo social.

Corroborando com os autores supracitados em defesa da corporeidade e do reconhecimento do corpo como produtor de saberes é que nos inspiramos para realização desse trabalho. Sabemos da necessidade de trazer essa temática para as salas de aulas como um tema transversal que possibilitará desafiar os educandos para buscar um olhar crítico sobre os conteúdos midiáticos, de forma que possam desenvolver uma atitude crítica perante os mesmos e assim serem responsáveis por suas idéias, crenças, atitudes e, consequentemente se respeitarem, se aceitarem, se amarem, assim como aos outros.

\section{Desenvolvimento metodológico}

A proposta desse estudo foi desenvolvida com os alunos do 9o ano (faixa etária entre 14 e 15 anos) da Escola Municipal Terezinha paulino, localizada na Rua Matinhos s/n, no Parque dos 
Coqueiros, na cidade de Natal/RN, no 2ㅇ semestre do ano letivo 2010. Metodologicamente foi realizado durante as aulas de educação física através de exposições dialógicas; leituras; seminários; palestras; e vivencia de diferentes técnicas corporais. Para a pretensão desse artigo estamos apresentando apenas parte do que foi desenvolvido com os educandos. Utilizamos inicialmente um questionário com questões abertas desvendando um diagnóstico sobre a compreensão de corpo pelos mesmos. Do universo de 82 alunos, obtivemos 75 respostas. Para auxiliar as reflexões contidas nesse texto trouxemos as falas dos alunos envolvidos na pesquisa.

"Relata-se de uma forma geral, os modos de compreensão corporal inscritos nas falas dos educandos: "o corpo deve ser musculoso," não gosto do meu corpo", "o corpo precisa de suplementação alimentar para repor as energias dos exercícios"; "o corpo precisa de muitos exercícios para ficar bem trabalhado e preparado para ser utilizado no trabalho e no dia-a-dia".

Esses entendimentos sobre o corpo foram revelados pelas experiências vividas que os mesmos até então costumavam terem. Fazendo referência a esses pensamentos e atitudes tatuados no fazer cotidiano desse educandos, é importante salientar que suas falas marcam o registro de uma história inscrita nesses corpos, onde se deixam alguns legados inspirados no modo de ser, ou seja: o corpo visto pela estrutura muscular é visibilizado como um artefato de funcionalidade e dependência de alguns ditames como o belo, o perfeito, o forte, dentre outros, que se instalou ao longo dos tempos, como produto de uma sociedade capitalista que tinha como força de trabalho, um corpo exercido como máquina a serviço do desenvolvimento. Reforçado por esse entendimento, temos na fala de outro sujeito, quando afirma: "o corpo precisa de muitos exercícios para ficar bem trabalhado e preparado para ser utilizado no trabalho e no dia-a-dia". E assim vai se construído esse modelo corporal de acordo com a época e história em que se vive.

As falas dos alunos confirma o pensamento de SANT'ANNA (2001) quanto à concepção de corpo que se firmou em nossa sociedade, em que o mesmo é vislumbrado pela sua materialidade corpórea, como instrumento a ser manipulado, corrigido e melhorado. O corpo nessa concepção é visto como uma máquina e o seu funcionamento restrito as leis da mecânica newtoniana, defendida por Descartes. Desse modo, o corpo como máquina é tratado como uma soma de partes, compreendidas isoladamente.

Ao se afirmar: "não gosto do meu corpo", pensa-se em seguida o motivo dessa irrelevância que se tem do mesmo, de que sentido não se gosta. Certamente não foram percebidos, codificados ou aprendidos com ele no que diz respeito aos seus sentimentos e emoções, além do prazer que o mesmo revela. Esse sentimento, ora revelado condiz com a fragilidade dessa não consciência ainda não instalada no corpo, porque o mesmo idealiza o modelo de corpo estereotipado pela mídia.

Como afirma LE BETRON (2003) vivemos no mundo da valorização da aparência física, existe um interesse exagerado pelo corpo, com o objetivo de corrigi-lo e submete-lo ao modelo idealizado pela mídia. Sendo assim, as pessoas não se aceitam como realmente são e buscam formas de intervenções que possam possibilitar as metamorfoses corporais desejadas. Nesse sentido, o mercado de produto e serviços vai se expandindo para atender as necessidades de um corpo "perfeito".

A importância demasiada a aparência e sua manutenção se retroalimentam na lógica do consumo, em que o estereótipo de corpo idealizado esta associado a imagens de juventude, beleza, saúde, sensualidade. Fato esse, contribui para expansão da comercialização dos produtos 
cosméticos, dos suplementos alimentares, cresce também a indústria da moda, e o interesse por uma educação para a saúde e o fitness (NÓBREGA, 2010).

Quando se diz que: "o corpo precisa de suplementação alimentar para repor as energias dos exercícios" se denuncia a dependência de algo para melhorar a sua performance, sintetizando mais uma vez o corpo a serviço de um consumo que se deseja ser possuído por novas tecnologias que se apropriam de forma, muitas vezes não percebido pelos sujeitos que se deixam ser seduzidos por ditames dessa atual sociedade, onde o corpo nunca saiu de cena.

A partir dessas falas incorporadas no modo de viver desses sujeitos, objetivamos tematizar sobre o corpo e seus saberes, utilizando um novo repertório de experiências, com práticas corporais, técnicas de relaxamento, eutonia, massagem, discussão de textos, apresentação de seminário, enfim.

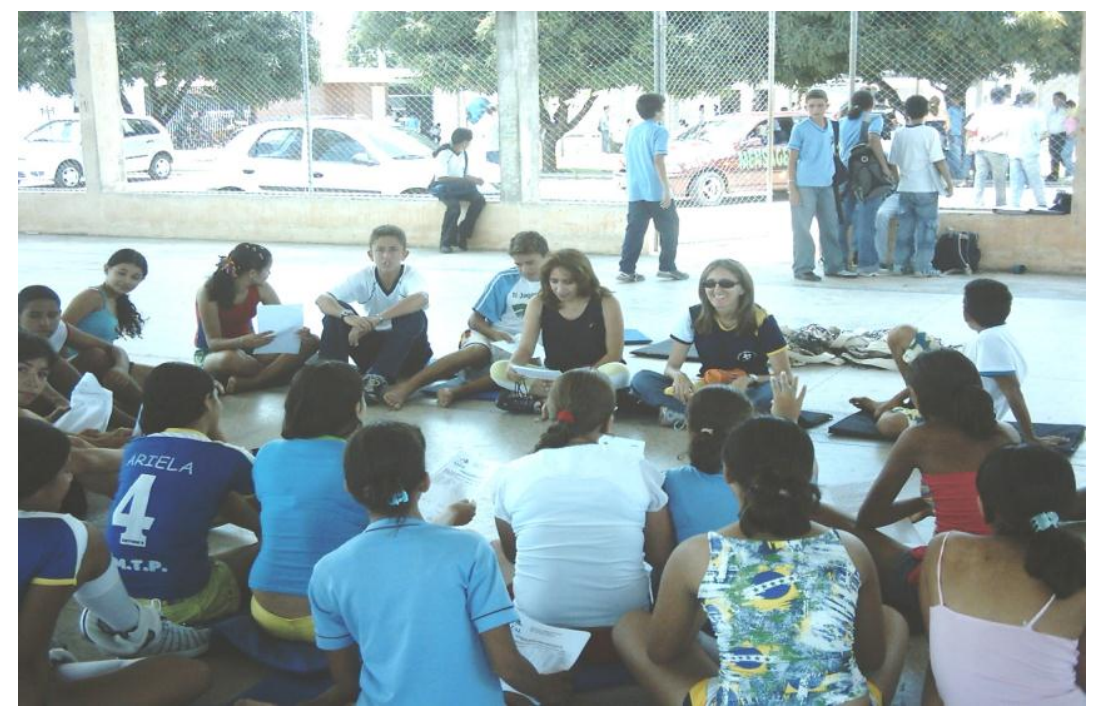

Figura 01

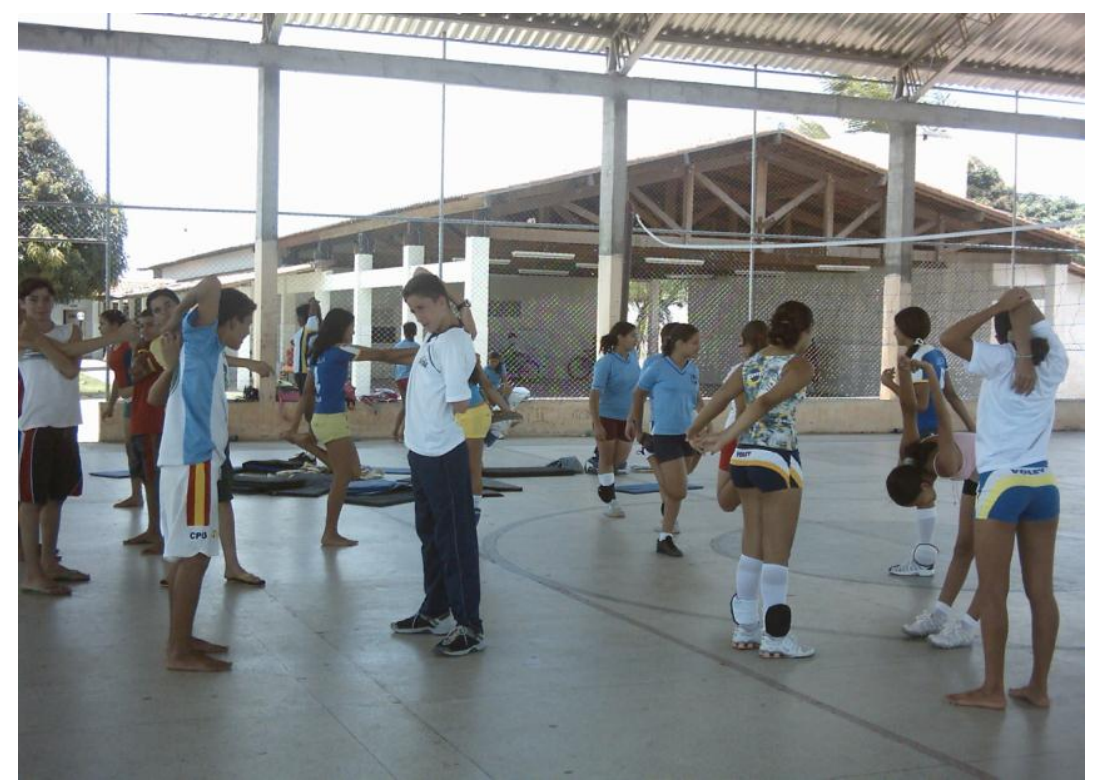

Figura 02 
Após o desenvolvimento e reflexão sobre a temática, fora construído uma maior significação sobre a essência do estudo, novo movimento pensante e dialógico exercido entre educador e educando. Percebeu-se que os sujeitos tiveram uma maior autonomia e fruição significativa sobre o seu modo de viver, pois ampliaram o universo desse estudo. Feitas estas intervenções, aplicou-se novamente as mesmas questões, em que se obteve um novo olhar, superando a visão instrumental de corpo.

Portanto novos relatos foram ao longo se construindo, desencadeando um novo discurso: "o corpo é a essência do meu ser", "o corpo é a minha casa", "me realizo com o modo de ser", "eu sou um corpo", enfim, agora dotados de uma maior autonomia de conhecimento, sentiram o gosto perceptivo da estesia corporal.

Quando se diz que "o corpo é a essência do meu ser", "é a minha casa", "me realizo com ele", "eu sou um corpo", percebem-se nesses discursos motivações existenciais, (re) pensando sua condição humana. Denota-se marcadamente o quanto ele tem aprendido e se tornado significante, não mais com uma forma objetiva, mas subjetiva e latente, elaborado pelo gestar exegético.

De acordo com NÓBREGA (2003), o corpo como espaço primeiro de visibilidade humana é o lugar em que estão tatuados a nossa história, é lugar também de criação da linguagem, de explosão de sentimentos, de emoção, de vida. Nesses termos, o mesmo não pode ser visto apenas pelos seus aspectos biológico, funcional e estrutural. O corpo não é coisa, objeto a ser manipulado de forma irrefletida. Quando se diz: "o corpo é a essência do meu ser", trata-se de dar-lhe um novo significado, não o vendo apenas como objeto, mais também como sujeito, um corpo vivo, um corpo com linguagem, desejo, emoção e história.

Ao afirmar: "eu sou um corpo", reconhece-se a condição de existência de um corpo próprio, diferenciando-se das outras pessoas, caracterizando-se pela corporeidade, que se revela na estesia do corpo, configurando a linguagem sensível. Os elementos da corporeidade: os desejos, as emoções, o saber incorporado são fundamentais para uma nova percepção da realidade (NÓBREGA, 2010).

Compreender o corpo na perspectiva da corporeidade é possível perceber que o mesmo possui uma singularidade própria, que somente se entende na convivência com outros corpos. É possível também, pensar o corpo em sua realidade paradoxal de objeto e sujeito da existência. "Cabe-nos viver o corpo em sua fenomenologia, voltarmos a ele nos voltando a nós mesmos, às nossas mais sutis experiências" (PORPINO, 2006, P.68). As experiências vividas permite-nos sermos sensíveis mesmo em uma sociedade que prioriza a racionalidade em detrimento da sensibilidade. O sensível define a essência do ser humano, singularizando-o, e se projeta como ponto de referência para as suas ações.

Considerando todas as significações hermenêuticas, até aqui pensadas e distribuídas, no decorrer desse processo epistemológico dos saberes corporais, é que certamente se acrescentou novos conhecimentos. Enfim, pode-se descobrir pelas inusitadas experiências a relevância desse estudo, uma vez que não se acaba por aqui. Mesmo sabendo que ele não pode responder a todos os anseios aqui presentes e nem cabe concluir, mas fica o legado de mais uma produção acadêmica que não pretende se der por acabado, mas provocar reflexões que refaça o caminho desses saberes, (re) apropriando-se da sua existência. 


\section{Considerações Finais}

Um estudo que procura refletir sobre a presença do corpo no âmbito da educação escolar, na busca de sua significação para o ser humano e para o fazer educativo, não pretende ser conclusivo. Deve provocar reflexões que leve a mudanças de valores, atitudes e comportamentos e que reconheça a complexidade do fenômeno em questão.

A educação torna-se uma força transformadora no projeto de humanização e emancipação do homem, focalizando como ponto central a corporeidade. A prática educativa enquanto processo de aprendizagem é um campo amplo de possibilidades de resgatar no ser humano a sensibilidade, a criatividade, o encontro consigo mesmo e com os outros. Desse modo, reconhece-se o ser humano como ser ativo e participante na construção da sua corporeidade, na busca dos anseios de transformação e libertação.

Ressalta-se que nesse estudo não se sugere novidades. Reconhecem-se professores desenvolvendo saberes nessa perspectiva aqui referenciada. Entretanto, o acesso a esses saberes ainda estão restritos a poucos. Nesse contexto, é que emerge a relevância desse estudo, que objetivou alcançar o universo escolar, contribuindo para que imprescindíveis transformações se faça na educação brasileira.

Com o trabalho desenvolvido com os alunos da Escola Municipal Terezinha Paulino, observou-se que através das discussões desenvolvidas, foi possível desenvolver valores e atitudes para a formação de novos comportamentos, mudança de mentalidades que contribuíram no processo de superação de preconceitos impostos pela cultura midiática. Os aspectos sensíveis e expressivos das práticas corporais (jogos, esportes, danças, etc.), como expressão da corporeidade, contribuíram para um (re) pensar do corpo e do movimento, na tentativa de superar a racionalização das práticas escolares e à objetalização do corpo imposta pela cultura do consumo.

\section{REFERÊNCIAS BIBLIOGRÁFICAS}

1. GONÇALVES, Augusta Salim. Sentir, pensar, agir: corporeidade e educação. São Paulo: papirus, 1994.

2. LE BRETON, David. Adeus ao corpo: Antropologia e sociedade. Tradução Marina Appenzeller. Campinas-SP: papirus, 2003.

3. MATURANA, H. Emoções e linguagem na educação e na política. Belo Horizonte: UFMG, 2002.

4. MORIN, Edgar. Em busca dos fundamentos perdidos. IN: MORIN, Edgar; NAIR, Sami. Uma política de civilização. Tradução Armando P. da Silva. Lisboa: Instituto Piaget, 1997.

5. NÓBREGA, T.P. corpos do tango: reflexões sobre gestos e cultura de movimento. IN: LUCENA, R.: SOUZA, E.F. (orgs.) Educação Física, esporte e sociedade. João pessoa: Editora universitária/ UFPB, 2003.

6. NÓBREGA, T.P. Uma fenomenologia do corpo. São Paulo: Editora Livraria da Física, 2010.

7. PORPINO, K. O. Dança é educação: interfaces entre corporeidade e estética. Natal/RN: EDUFRN - Editora da UFRN, 2006. 
8. SANT'ANNA, Denise Bernuzzi. É possível realizar uma história do corpo? IN: SOARES, C.L. (org). Corpo e história. Campinas-SP: autores associados, 2001.

9. SANTIN, Sílvio. Perspectivas na visão da corporeidade. IN: MOREIRA, W.W (org.) Educação Física \& Esporte: perspectivas para o século XXI. Campinas, SP: papirus, 1993.

10. SILVA, A. M. Corpo, ciência e mercado: reflexões acerca da gestação de um novo arquétipo da felicidade. Campinas- SP: Autores associados: Florianópolis: Editora UFSC, 2001. 